\title{
Double-Incision Approach and Early Rehabilitation in a Complicated Bicondylar Tibial Plateau Fracture: A Case Report
}

\author{
Saverio Affatato ${ }^{a}$ Maurizio Montalti ${ }^{b}$ Claudio Masetti ${ }^{b}$ Federico Giardina ${ }^{b}$ \\ Alessandra Sudanese ${ }^{a, b}$ \\ ${ }^{a}$ Orthopaedic-Traumatology and Prosthetic Surgery and Revisions of Hip and Knee Implants, and \\ ${ }^{b}$ Medical Technology Laboratory, Rizzoli Orthopaedic Institute, Bologna, Italy
}

\section{Significance of the Study}

- In this report, a bicondylar tibial fracture treated with a two-incision approach and double-plate osteosynthesis provided strong fracture stabilization and allowed an early mobilization with aggressive rehabilitation. The two-incision technique prevented avascular wound complications and/or infection.

\section{Keywords}

Bicondylar tibial fracture $\cdot$ Association for Osteosynthesis classification · Rehabilitation

\section{Abstract}

Objective: The main goal of this case was to report the treatment of bicondylar fractures of the tibial plateau and the restoration of the metaphyseo-diaphyseal dissociation. Clinical Presentation and Intervention: A 54-year-old male who was cycling had a road accident that caused a closed fracture of the right tibial plateau and proximal fibula diagnosed by $X$ rays. The patient underwent surgery and was immobilized with a long-leg splint for 4 weeks. After immobilization, aggressive rehabilitation was done. Progressive quadriceps strengthening, movements to improve symmetrical weight bearing, and functional activities were performed. The patient improved muscle strength and obtained high scores for gait and balance in a relatively short time. Conclusion: In

\begin{tabular}{ll}
\hline KARGER & (c) 2017 S. Karger AG, Basel \\
$\begin{array}{l}\text { E-Mail karger@karger.com } \\
\text { www.karger.com/mpp }\end{array}$ & $\begin{array}{l}\text { This is an Open Access article licensed under the terms of the } \\
\text { Creative Commons Attribution-NonCommercial 3.0 Un- } \\
\text { ported license (CC BY-NC) (www.karger.com/OA-license), } \\
\text { applicable to the online version of the article only. Distribu- } \\
\text { tion permitted for non-commercial purposes only. }\end{array}$
\end{tabular}

this report, a bicondylar tibial fracture treated with a twoincision approach and a double-plate osteosynthesis provided strong fracture stabilization and thereby allowed an early mobilization with aggressive rehabilitation.

(c) 2017 S. Karger AG, Basel

\section{Introduction}

Fractures of the bicondylar tibial plateau are serious injuries that may occur after high-energy trauma [1]. They are often difficult to treat, and any treatment protocol should aim at restoring articular congruity. In a normal knee, the physiological alignment is in slight valgus $\left(170^{\circ}-\right.$ $177^{\circ}$ ), and for this reason, most of the load is mostly transmitted through the lateral femoral condyle and the lateral tibial plateau [2]. The tibial plateau fractures are commonly caused due to repetitive accumulation of stress and/or trauma in the form of high-energy forces in valgus or var-

Dr. Saverio Affatato

Laboratorio di Tecnologia Medica, Istituto Ortopedico Rizzoli

Via di Barbiano 1/10

IT-40136 Bologna (Italy)

E-Mail affatato@ tecno.ior.it 

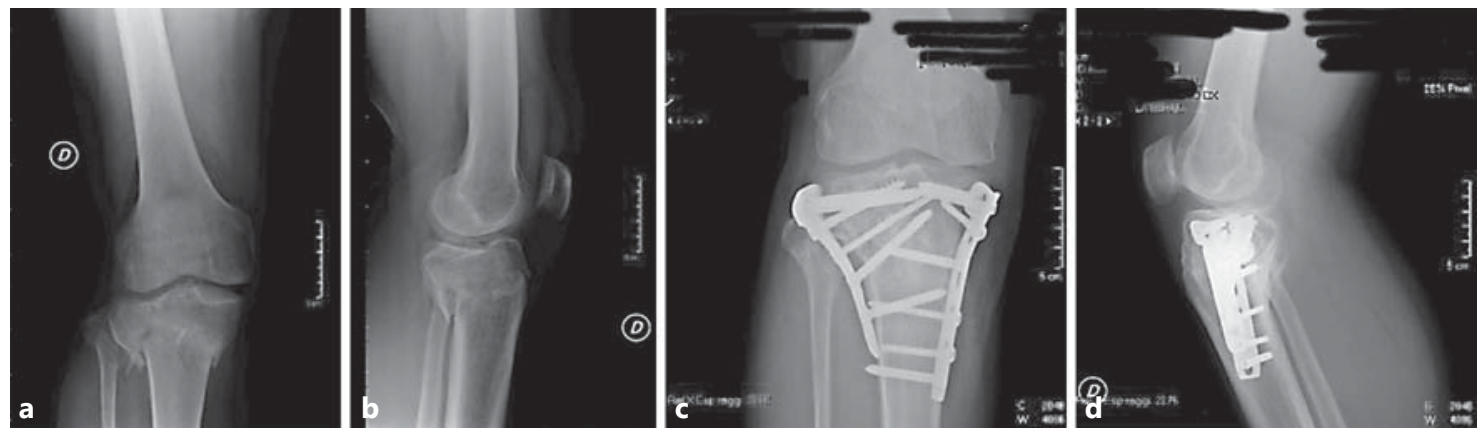

Fig. 1. a, b Anterior and lateral view of the preoperative X-rays. c, $\mathbf{d}$ Anterior and lateral view of the postoperative $\mathrm{X}$-rays.

us (i.e., road trauma when a pedestrian is hit by the bumper of a car) in the form of high-energy forces with axial and rotational compression [3]. The results of these traumas can be a mono or bicondylar tibial plateau fracture, depression of 1 or both plates and/or bone breakage involving cruciate ligaments, menisci, and the joint capsule. The operative treatment of these fractures includes anatomic reduction, alignment, and stable fixation to allow early motion [4]. The Schatzker classification system [5] is the most common classification used in international literature; it is based on the location and extent of the fracture and associated depression of the bone. The Association for Osteosynthesis (AO) classification system is common too and it is a general alphanumeric classification, which includes 3 main groups (divided into relative subgroups): (a) extra articular fractures, (b) partial articular fracture, and (c) complete articular fractures [6].

The aim of the present study was to evaluate the functional outcomes following operative stabilization of a complicated bicondylar tibial plateau fracture.

\section{Case Report}

A 54-year-old male who was cycling experienced a road accident that caused a closed fracture of the right tibial plateau and proximal fibula diagnosed by X-rays. A palsy of the lateral sciatic popliteal nerve was present at first aid access. A transkeletal traction wire was immediately applied to the calcaneus in the emergency unit, and then the limb was placed on a Zuppinger chassis with a $4-\mathrm{kg}$ tensile. The sciatic palsy resolved within about $4 \mathrm{~h}$. The patient was affected by a typical type $\mathrm{V}$ fracture (split bicondylar fracture) according to the Schatzker classification and a C1 fracture according to the AO classification. An X-ray and CT scan confirmed a bicondylar fracture (Fig. 1a, b). The patient was informed that his case would be submitted for publication, and he gave his consent.

\section{Surgical Technique}

To allow soft tissue swelling to decrease, the surgical procedure was performed 3 days after trauma. The surgery procedure was performed in 2 steps; initially, a posteromedial longitudinal incision to the knee was performed. Pes anserinus was partially detached, and a limited dissection of the medial collateral ligament was performed. After the capsule had been opened, medial meniscus uplift was performed in order to obtain an evaluation of the medial joint plate. Fracture reduction and temporary Kirschner-wire synthesis were done. The ultimate synthesis was realized with a Depuy-Synthes ${ }^{\circledR}$ LCP T-shaped plate plus 7 screws; then an arcuate-shaped incision in the lateral compartment of the knee was performed. Soft tissues were detached from the tibial crest, and capsule opening with external meniscus uplift was realized. A large central osteochondral fragment of the lateral tibial plateau that sunk in the metaphysis was lifted and reduced by the surgeon. A temporary fixation with Kirschner wires was performed. A definitive synthesis was carried out with a Depuy-Synthes ${ }^{\circledR}$ LCP L-shaped plate plus 6 screws (Fig. 1c, d). Finally, the pes anserinus, medial, and lateral menisci were reconnected and sutured. Before skin closure, 2 redons were applied. After surgical procedure and after immobilization with a long-leg splint for 3 weeks without any movement, an aggressive and early rehabilitation were done in order to improve muscle strength, proprioception, and range of motion (ROM), and to reduce pain and swelling. A series of electrical pulses (electrostimulation) to induce the contraction of the muscle was applied in order to strengthen the quadriceps. Partial weight was allowed at 12 weeks after surgery, and other activities such as cycling and elastic tubing exercises were started. Total free-weight bearing was allowed 5 months after the surgical procedure. Quadriceps, hamstring, and calf raise exercises were introduced in the exercise program to stabilize and strengthen the knee. Six months after surgery, the patient showed a normal flexion range $\left(0-130^{\circ}\right)$ that represented an outstanding outcome for a $\mathrm{V}$ type fracture according to the Schatzker classification [5]. The functional outcome was measured using the Knee injury and Osteoarthritis Outcome Score questionnaire at the 1-year follow-up. The patient walked without pain and limp; the knee was slightly swollen but stable. 


\section{Discussion}

Although several fixation techniques have been explored for the treatment of bicondylar tibial plateau fractures, a two-incision double-plating technique remains the recommended procedure for such injuries [4]. A revision of international clinical records performed by British surgeons [7] shows a lack of general agreement about the best treatment and related outcomes in articular proximal tibia fractures, while a warning to avoid wide skin incisions seems to be generally recommended. In this case report, the patient with bicondylar tibial plateau fractures treated with dual plating via a two-incision technique resulted in satisfactory clinical and radiologic outcomes, with an acceptable complication risk rate. Yao et al. [8] support that a single external locked plate can be used to stabilize both tibial condyles; conversely, other authors $[9,10]$ suggest alternative approaches that can be used alone or in combination with a usual approach. The postoperative results of the present study showed that the bicondylar tibial plateau fracture with articular comminution and dual-incision osteosynthesis technique had a significant effect on functional outcomes: excellent knee function and a high patient satisfaction regarding quality of life improvement.

\section{Conclusions}

In this case report, the patient had satisfactory clinical and radiologic outcomes, with no complications. The patient achieved a greater ROM, improved muscle strength, and obtained higher scores for gait and balance in a relatively short time.

\section{References}

1 Berkson EM, Virkus WW: High-energy tibial plateau fractures. J Am Acad Orthop Surg 2006; 14:20-31.

2 Ruffolo MR, Gettys FK, Montijo HE, et al: Complications of high-energy bicondylar tibial plateau fractures treated with dual plating through two incisions. J Orthop Trauma 2015;29:85-90

3 Tsuchie H, Okada K, Nagasawa H, et al: Bilateral stress fracture of the fibulae and periostitis of the tibiae. Med Phys 2010;19:490-492.
4 Zhang Y, Fan D, Ma B, et al: Treatment of complicated tibial plateau fractures with dual plating via a 2 -incision technique. Orthopedics 2012;35:e359-e364.

5 Schatzker J, McBroom R, Bruce D: The tibial plateau fracture. Clin Orthop Relat Res 1979; 138:94-104.

6 Gicquel T, Najihi N, Vendeuvre T, et al: Tibial plateau fractures: reproducibility of three classifications (Schatzker, AO, Duparc) and a revised Duparc classification. Orthop Traumatol Surg Res 2013;99:805-816.

7 McNamara IR, Smith TO, Shepherd KL, et al: Surgical fixation methods for tibial plateau fractures. Cochrane Database Syst Rev 2015; 15:CD009679.
8 Yao Y, Lv H, Zan J, et al: A comparison of lateral fixation versus dual plating for simple bicondylar fractures. Knee 2015;22:225-229.

9 Weil YA, Gardner MJ, Boraiah S, et al: Posteromedial supine approach for reduction and fixation of medial and bicondylar tibial plateau fractures. J Orthop Trauma 2008;22: 357-362.

10 Johnson EE, Timon S, Osuji C: Surgical technique: Tscherne-Johnson extensile approach for tibial plateau fractures. Clin Orthop Relat Res 2013;47:2760-2767. 